\title{
A Traffic Light Approach to Solvency Measurement of Swiss Occupational Pension Funds
}

\author{
Alexander Braun, Przemysław Rymaszewski and Hato Schmeiser \\ Institute of Insurance Economics, University of St. Gallen, Kirchlistrasse 2, CH-9010, St. Gallen, \\ Switzerland. \\ E-mails: alexander.braun@unisg.ch,przemyslaw.rymaszewski@unisg.ch, hato.schmeiser@unisg.ch
}

In this paper, we combine a stochastic pension fund model with a traffic light approach to solvency measurement of occupational pension funds in Switzerland. Assuming normally distributed asset returns, a closed-form solution can be derived. Despite its simplicity, we believe the model comprises the essential risk sources needed in supervisory practice. Owing to its ease of calibration, it is well suited for a regulatory application in the fragmented Swiss market, keeping costs of solvency testing at a minimum. We calibrate and implement the model for a small sample of ten Swiss pension funds in order to illustrate its application and the derivation of traffic light signals. In addition, a sensitivity analysis is conducted to identify important drivers of the shortfall probabilities for the traffic light conditions. Although our analysis concentrates solely on Switzerland, the approach could also be applied to similar pension systems.

The Geneva Papers (2011) 36, 254-282. doi:10.1057/gpp.2011.3

Keywords: occupational pension funds; solvency regulation; traffic light approach

\section{Introduction}

The recent crisis in the global financial markets hit not only banks and insurers but also the pension fund industry. The resulting underfunding of a large number of pension schemes triggered a discussion about the rearrangement of prudential regulation and supervision for occupational pension funds in Switzerland. The obligatory character of occupational pension plans for the majority of Swiss employees, the large volume invested through them (according to the Swiss Federal Statistical Office, in 2008 the aggregated book value of assets was approximately equal to the Swiss GDP), as well as significant social costs linked to potential insolvencies demonstrate that this debate is not exclusively political. Instead, a solvency test for pension funds is of considerable relevance to employees, employers and pensioners. Supervision and regulation of pensions in Switzerland is currently conducted at the cantonal level. ${ }^{1}$ The main task of these regulators is to ensure that the pension funds comply with the legal requirements. Besides, they receive the annual reports and the report of an independent occupational pension expert, whose duty is the valuation of a fund's technical liabilities. The expert also examines whether or not a fund is able to cover its liabilities. Comprehensive solvency regulation, however, is not present for occupational pension funds in

\footnotetext{
${ }^{1}$ See also Gugler (2005).
} 
Switzerland, although banks and insurance companies have to adhere to Basel II and the Swiss Solvency Test (SST), respectively. ${ }^{2}$ This paper is an attempt to address this issue. We suggest an efficient solvency test for occupational pension funds, providing condensed information for the stakeholder groups instead of prescribing regulatory capital. For this purpose, we adopt a model for pension funds under stochastic rates of return and combine it with a traffic light approach, allowing an efficient comparison of the risks inherent to different funds as well as a comprehensible communication of results of the solvency test. This signal-based approach can be used not only to support the supervisory process, but also to facilitate an increased level of market discipline. However, more transparency within the pension fund market can intensify the latter only if insureds are both capable of interpreting the received signal and of taking actions as a consequence of the information they receive.

The literature with regard to stochastic pension fund modeling has been strongly influenced by the work of O'Brien ${ }^{3}$ and Dufresne. ${ }^{4}$ While the former proposes a continuous-time approach, the early model of Dufresne operates in a discrete-time environment. This original discrete-time model has subsequently been applied and extended in several papers. Haberman ${ }^{5}$ introduces time delays with regard to additional contributions for unfunded liabilities and, in a consecutive paper, Haberman ${ }^{6}$ examines $^{2}$ the effects of changes in the valuation frequency for the pension fund's assets and liabilities. Furthermore, Zimbidis and Haberman ${ }^{7}$ use the model with time delays to derive expectations and variances for fund and contribution level distributions. In two additional publications, Haberman ${ }^{8}$ drops the assumption of independent and identically distributed (iid) asset returns in favour of a first-order autoregressive process and utilizes the model to compare different pension funding methods. In contrast to the discrete-time focus of the majority of papers, Haberman and Sung ${ }^{9}$ present and employ a continuoustime model to simultaneously minimise an objective function for contribution rate and solvency risk. Subsequently, Haberman ${ }^{10}$ reverts to a discrete-time version with iid asset returns and analyses funding approaches to control contribution rate risk of definedbenefit pension funds. Cairns ${ }^{11}$ extends previous work by turning to the fund's asset allocation strategy as a means of controlling funding level variability. In a later paper, Cairns ${ }^{12}$ presents a pension fund model in continuous-time with continuous adjustments to the asset allocation and contribution rate. A similar model but with stochastic benefit outgo is again discussed by Cairns, ${ }^{13}$ while Cairns and Parker ${ }^{14}$ apply a discrete-time

\footnotetext{
${ }^{2}$ See, for example, Eling et al. (2008).

3 O'Brien (1986, 1987).

${ }^{4}$ Dufresne (1988, 1989, 1990).

5 Haberman (1992).

${ }^{6}$ Haberman (1993a).

${ }^{7}$ Zimbidis and Haberman (1993).

${ }^{8}$ Haberman (1993b, 1994).

${ }^{9}$ Haberman and Sung (1994).

${ }^{10}$ Haberman (1997).

${ }^{11}$ Cairns (1995).

12 Cairns (1996).

13 Cairns (2000).

${ }^{14}$ Cairns and Parker (1997).
} 
approach and compare the effect of a change from iid to autoregressive returns on the variability of funding level and contribution rates. Finally, Bédard and Dufresne ${ }^{15}$ show that the dependence of successive rates of return can have a considerable effect on the model results in a multi-period setting.

The model we present is based on the discrete-time framework which has been frequently employed in the literature in order to analyse issues, such as contribution rate risk or behaviour of the funding level over time. However, it has not been previously considered in the context of solvency measurement. We adapt the model so as to capture the particularities associated with the occupational pension fund system in Switzerland and demonstrate that its simplicity and ease of calibration are advantages for an application as a regulatory standard model in this fragmented market. The model enables us to estimate shortfall probabilities which are then funneled into a traffic light approach in order to send a signal to stakeholder groups, which carries condensed information about a fund's financial strength and is straightforward to interpret, even for less sophisticated claim holders. Although the scope of our analysis is limited to Switzerland, both the model itself and the insights from its application can be transferred to similar pension systems.

The remainder of this paper is organised as follows. The next section sets the stage with a brief introduction to the particularities of Switzerland's occupational pension fund system. The stochastic pension fund model which forms the basis for the proposed solvency test is presented in the third section followed by an explanation of the traffic light approach to solvency measurement. The fifth section comprises an exemplary calibration of the model and an illustration of its application by computing shortfall probabilities and deriving the traffic lights for a small sample of ten Swiss pension funds. A sensitivity analysis is then conducted in the sixth section in order to identify important drivers of the shortfall probabilities for the traffic light conditions. The seventh section focuses on the supervisory review process. Some additional considerations concerning a potential implementation in Switzerland are provided in the penultimate section. Finally, in the last section, we conclude.

\section{The particularities of the Swiss occupational pension fund system}

The Swiss pension system comprises three pillars. ${ }^{16}$ The first pillar is earnings-related and embedded in the public social security scheme; the second pillar relates to the mandatory occupational pension fund system; ${ }^{17}$ the third pillar consists of additional benefits that need to be accumulated individually. ${ }^{18}$ Our paper focuses on the second pillar which is governed by the Swiss occupational pension law (abbreviated in German: $\mathrm{BVG}^{19}$ and $\mathrm{BVV}^{20}$ ). At the heart of the second pillar, which, apart from

\footnotetext{
15 Bédard and Dufresne (2001).

${ }^{16}$ See Brombacher Steiner (1999).

${ }^{17}$ Participation in the occupational pension system is mandatory for all employees of age 18 or older who earn a minimum annual salary of 20,520 CHF (Art. 7 BVG).

18 See, for example, OECD (2009).

19 BVG (2009).

${ }^{20}$ BVV2 (2009).
} 
retirement pensions, also provides widow(er) and invalidity pensions, are the occupational pension funds (in German: Vorsorgeeinrichtungen).

The vast majority of occupational pension funds in Switzerland takes the legal form of private trusts, where the employees have a right of parity participation in the administrative council (Art. 55 BVG). ${ }^{21}$ Apart from single-employer pension funds, which are run exclusively for the employees of one company, the specific structure of the Swiss economy with many small and medium-sized businesses necessitates so-called multi-employer pension funds (in German: Sammeleinrichtungen). ${ }^{22}$ This relieves small businesses from the burden of setting up their own pension fund, because they can join a multi-employer fund which bundles the occupational pension schemes of several independent firms. ${ }^{23}$ A change of pension fund can only be completed by the employer with the agreement of the majority of employees. The second pillar is covered by a guarantee fund (in German: Sicherheitsfonds $B V G$ ), with the main purpose of subsidizing schemes with an adverse age structure and guaranteeing the obligatory payments of defaulted funds.

Compulsory pension contributions are based on the so-called coordinated salary ${ }^{24}$ (in German: koordinierter Lohn) of the employee and the employer has to bear at least half of each installment (Art. 8 and Art. 66 BVG). ${ }^{25}$ These regular payments are credited to a pension account (in German: Altersguthaben) and at least compounded with an obligatory minimum rate of return (currently 2 per cent). Once the insured reaches the retirement age of 65 for men or 64 for women (Art. 13 BVG), the obligatory pension annuity is calculated by multiplying the annuity conversion rate, which is currently 6.8 per cent, with the final balance of the pension account (Art. 14 BVG). ${ }^{26}$ The Swiss Federal Council (in German: Der Schweizerische Bundesrat) determines both the minimum interest rate and the conversion rate at two- and ten-year intervals, respectively. ${ }^{27}$ In general, Swiss occupational pension funds can be set up either as defined-contribution or as defined-benefit plans.

One important aspect of the occupational pension fund system in Switzerland is that funds are legally allowed to temporarily operate with a deficit of assets relative to liabilities (Art. 65c BVG). Such an underfunding of liabilities is indicated by the coverage ratio, that is, the proportion of the market value of assets over technical liabilities, falling below 100 per cent (Art. 44 BVV2). However, the tolerance of a temporary underfunding is strictly linked to the condition that a pension fund continues its ongoing obligatory pension payments and takes action to restore full

${ }^{21}$ Pension funds of the federation, cantons and municipalities are institutions under public law.

22 See Swiss Federal Statistical Office (2009).

${ }^{23}$ Employers are obliged to either establish a firm-specific pension fund or to join multi-employer fund with the consent of their employees (Art. 11 BVG).

${ }^{24}$ Currently the coordinated salary is the part of an employee's annual income between 23,940 and $82,080 \mathrm{CHF}$.

${ }^{25}$ Voluntary payments in excess of the compulsory contributions are possible.

${ }^{26}$ The pension funds can decide to provide annuities over and above the obligatory level.

${ }^{27}$ When determining the minimum interest rate, the Swiss Federal Council takes into account the recent development of the returns of marketable investments, with a particular focus on government bonds, corporate bonds, equities and real estate (Art. 15 BVG). Mortality improvements are accounted for through an adjustment of the conversion rate. 
coverage within an adequate time horizon. In addition, the pension fund has to promptly inform the regulator, the employer, the employees and the pensioners about the magnitude and causes of the asset shortage as well as countermeasures that have been initiated. The pension fund has to eliminate the deficit itself as the guarantee fund can merely intervene in case of insolvency (Art. 65d BVG). For this purpose, the fund can raise additional contributions from the employer and the employees to rectify the deficit. If and only if all other actions prove insufficient, the fund is allowed to go below the obligatory minimum interest rate by up to 0.5 per cent for no longer than five years.

\section{The model framework}

We suggest building a solvency framework for occupational pension funds around underfunding probabilities, at the centre of which we need a stochastic pension fund model. While advanced internal models could be allowed for the supervision of pension funds with sophisticated risk management know-how and processes, the requirements of a regulatory standard model suggest an approach that concentrates on the most essential risk drivers. The complexity of such a standard model should be kept within adequate limits so that the introduction of the solvency regulation does not cause an unjustifiably large increase in personnel and infrastructure cost, especially for smaller occupational pension funds. Apart from that, a properly developed simple model is capable of capturing the main determinants of pension fund activity. ${ }^{28}$ Moreover, the feasibility of the whole concept depends on sufficient data being available for calibration. This is more likely to be the case for an approach which entirely relies on observable variables such as accounting figures. With these considerations in mind, we decide in favour of a discrete-time model that ensures universal applicability, cost-efficient implementation and straightforward calibration. ${ }^{29}$ The model we present is based on the work of Cairns and Parker. In the following, we adapt it to the specific characteristics of occupational pension funds in Switzerland and combine it with a traffic light approach for the assessment of shortfall probabilities in order to construct a pragmatic solvency test.

Consider a one-period evaluation horizon and continuous compounding. If the occupational pension fund is assumed to have a stationary membership and all cash flows are exchanged at the beginning of the period, the asset process of the pension fund can be described as follows:

$$
\tilde{A}_{1}=\exp \left(\tilde{r}_{1}\right)\left(A_{0}+C_{0}-B_{0}\right)
$$

where

- $\tilde{A}_{1}$ : stochastic market value of the assets in $t=1$,

- $\tilde{r_{1}}$ : stochastic return on the assets between $t=0$ and $t=1$,

\footnotetext{
${ }^{28}$ See, for example, Cairns and Parker (1997).

${ }^{29}$ Equivalent formulations in continuous time can be found in the literature. See, for example, Cairns (1996).
} 
- $A_{0}$ : market value of the assets in $t=0$,

- $C_{0}$ : contributions for the period between $t=0$ and $t=1$,

- $B_{0}$ : benefit payments for the period between $t=0$ and $t=1$.

The aggregated asset return consists of normally distributed returns for each asset class in the fund's portfolio:

$$
\tilde{r}_{1}=\sum_{i=1}^{n} w_{i} \tilde{r}_{i},
$$

with $\tilde{r_{i}} \sim N\left(\mu_{i}, \sigma_{i}\right), \forall i \in\{1, \ldots, n\}$, where

- $w_{i}$ : portfolio weight for asset class $i$,

- $\tilde{r}_{i}$ : return of asset class $i$ between $t=0$ and $t=1$,

- $n$ : number of asset classes in the portfolio.

Note that for some asset classes, the assumption of normally distributed returns is merely an approximation. ${ }^{30}$ However, it will enable us to derive a closed-form solution, which we consider a very valuable aspect of a standard solvency model.

Since occupational pension funds commonly have a large pool of employees and pensioners, their liabilities are fairly well diversified and consequently relatively stable. Hence, the crucial source of risk is constituted by a pension fund's asset allocation and a deterministic approach for the liabilities is justifiable. In general, the value of the liabilities in $t=0$ is the present value of the stochastic future cash flows from the fund to those insured. These cash outflows are estimated actuarially, taking into account the age structure and mortality profile of the fund as well as the targeted rate of return, which needs to be equal to or greater than the obligatory minimum. Although an actuarial technical interest rate is commonly used for discounting in this context, it is more adequate to apply the current interest rate term structure. Therefore, we incorporate the market value of the liabilities into our model and define the corresponding yield as the valuation rate of interest $i_{v}$. Issues resulting from a potential misestimation of the pension liabilities will be addressed in the Section "Sensitivity analysis". If the liabilities are assumed to be continuously compounded at $i_{v}$, we have the following relationship:

$$
L_{1}=\exp \left(i_{\mathrm{v}}\right)\left(L_{0}+R C_{0}-B_{0}\right)
$$

where

- $L_{1}$ : market value of the liabilities in $t=1$,

- $i_{\mathrm{v}}$ : interest rate for the valuation of the liabilities,

- $L_{0}$ : market value of the liabilities in $t=0$,

- $R C_{0}$ : regular contributions for the period between $t=0$ and $t=1$.

The assumptions of normally distributed asset returns and deterministic liabilities could be relaxed by resorting to numerical solutions, for example, via a Monte-Carlo

\footnotetext{
${ }^{30}$ See, for example, Officer (1972).
} 
simulation framework. In that case, many different distributional assumptions and dependency structures could be incorporated. Similarly, a numerical solution would allow the introduction of a longer time horizon and intermediate time steps or a continuous-time framework. ${ }^{31}$

The contributions between $t=0$ and $t=1, C_{0}$, consist of two distinct elements:

$$
C_{0}=R C_{0}+A C_{0}
$$

with

$$
A C_{0}=\alpha \max \left[L_{0}-A_{0}, 0\right],{ }^{32}
$$

where

- $A C_{0}$ : additional contributions between $t=0$ and $t=1$ for the recovery of a deficit in $t=0$,

- $\alpha$ : fraction of the deficit in $t=0$, which will be covered between $t=0$ and $t=1$.

At the beginning of each period due additional contributions are determined based on the current deficit of assets relative to liabilities. Hence, $A C_{0}$ also accounts for additional contributions remaining from prior deficits. Consider, for example, a deficit in $t=-1$. The resulting additional contribution $A C_{-1}$ will increase the value of the assets in $t=0, A_{0}$, which then forms the basis for the calculation of $A C_{0}$. Therefore, if $A C_{-1}$ together with the development of the assets and liabilities between $t=-1$ and $t=0$ was sufficient to eliminate the deficit, there would be no need for further additional contributions and $A C_{0}$ would be zero.

Additional contributions are subject to two restrictions. First of all,

$$
\alpha \geqslant \alpha^{\min }=\frac{1}{\theta}
$$

which implies

$$
A C_{0}^{\min }=\alpha^{\min } \max \left[L_{0}-A_{0}, 0\right]
$$

where

- $\theta$ : maximum number of years for the elimination of the deficit (set by the regulator), - $\alpha^{\text {min }}$ : minimum fraction of the deficit in $t=0$, which needs to be covered between $t=0$ and $t=1$.

The restriction in Inequality (6) implies that deficits have to be eliminated within an adequate time horizon (see previous section), which will be set by the regulator

\footnotetext{
${ }^{31}$ See Bühlmann (1996) for the calculation of ruin probabilities in a similar context, applying a multidimensional geometric Brownian motion for the asset dynamics.

${ }^{32}$ Note that a negative value of $L_{0}-A_{0}$ implies a positive fluctuation reserve or a positive amount of uncommitted funds.
} 
through the choice of $\theta .{ }^{33}$ As a consequence, additional contributions in the period under consideration must not fall below a certain minimum, $A C_{0}^{\mathrm{min}}$, as defined in (7), since otherwise the elimination of the deficit would take too long. Intuitively, the fewer years available for the fund to restore its coverage ratio at least to unity, the higher the scheduled additional contributions for each year have to be.

Furthermore,

$$
A_{0} \geqslant A_{0}^{\min }=\beta L_{0},
$$

which implies

$$
\begin{aligned}
A C_{0}^{\max } & =\max \left[L_{0}-\beta L_{0}, 0\right] \\
& =\max \left[(1-\beta) L_{0}, 0\right],
\end{aligned}
$$

with

- $\beta$ : lowest acceptable coverage ratio $A_{0}^{\min } / L_{0}$ (set by the regulator).

Excessive additional contributions are disputable, since they transfer the investment risk from the pensioners to the employees and employers. Accordingly, Inequality (8) accounts for the fact that deficits can only be healed by means of additional contributions up to a certain amount. For instance, consider a case in which the value of assets falls to zero. Clearly, a restructuring of the pension fund is not feasible in this case. Hence, in order to protect those insured from having to pay an unacceptably large amount of additional contributions into a pension fund in major distress, we define a lower limit for the assets $A_{0}^{\text {min }}$ (a fixed percentage of the pension fund's liabilities), which puts a cap on additional contributions per period. This amount, termed $A C_{0}^{\max }$, is defined in Eq. (9) and based on $\beta$, that is, the lowest coverage ratio acceptable by the regulator. Usually, $0 \leqslant \beta \leqslant 1$, and the lower $\beta$, the higher the maximum amount of additional contributions that can be charged by the pension fund in any given period. ${ }^{34}$ If the assets fall below the threshold $A_{0}^{\min }$, the fund will ceteris paribus be unable to rectify the deficit within a single period. In addition, if $A C_{0}^{\mathrm{min}}$ exceeds $A C_{0}^{\max }$, which is theoretically possible, particularly for high values of $\alpha$ (low values of $\theta$ ) and $\beta$, the pension fund faces an existential funding problem, since it would be required to collect a larger amount of additional contributions than it is actually allowed to.

Under the above assumptions, the assets at the end of the evaluation period are log-normally distributed with:

$$
\mathrm{E}\left[\tilde{A}_{1}\right]=\mathrm{E}\left[\exp \left(\tilde{r}_{1}\right)\left(A_{0}+C_{0}-B_{0}\right)\right]
$$

\footnotetext{
${ }^{33}$ In Switzerland this time period is not legally defined. In current practice, however, a five-year span seems to have emerged as convention.

${ }^{34}$ Note that theoretically $\beta$ could also exceed one. In such a case, additional contributions would be ruled out by our model framework. To see this, refer to Eq. (9).
} 
which is equivalent to

$$
\mathrm{E}\left[\tilde{A}_{1}\right]=\exp \left(\mathrm{E}\left[\tilde{r}_{1}\right]+\frac{\operatorname{var}\left[\tilde{r}_{1}\right]}{2}\right)\left(A_{0}+C_{0}-B_{0}\right)
$$

and

$$
\begin{aligned}
\operatorname{var}\left[\tilde{A}_{1}\right]= & \operatorname{var}\left[\exp \left(\tilde{r}_{1}\right)\left(A_{0}+C_{0}-B_{0}\right)\right] \\
\operatorname{var}\left[\tilde{A}_{1}\right]= & \left(A_{0}+C_{0}-B_{0}\right)^{2} \\
& \times \exp \left(2 \mathrm{E}\left[\tilde{r}_{1}\right]+\operatorname{var}\left[\tilde{r}_{1}\right]\right)\left(\exp \left(\operatorname{var}\left[\tilde{r}_{1}\right]\right)-1\right) .
\end{aligned}
$$

Hence, in order to calculate the first two central moments, which entirely determine the asset distribution in $t=1$ under the assumption of normally distributed returns, estimates for $\mathrm{E}\left[\tilde{r}_{1}\right]$ and $\operatorname{var}\left[\tilde{r}_{1}\right]$ are required. Using Eq. (2), mean and variance for the returns of the aggregated asset portfolio can be calculated in the following manner:

$$
\mathrm{E}\left[\tilde{r}_{1}\right]=\mathrm{E}\left[\sum_{i=1}^{n} w_{i} \tilde{r}_{i}\right]=\sum_{i=1}^{n} w_{i} \mathrm{E}\left[\tilde{r}_{i}\right]
$$

and

$$
\operatorname{var}\left[\tilde{r}_{1}\right]=\sigma_{\tilde{r}_{1}}^{2}=\operatorname{var}\left[\sum_{i=1}^{n} w_{i} \tilde{r}_{i}\right]=\sum_{i=1}^{n} \sum_{j=1}^{n} w_{i} w_{j} \rho_{\tilde{r}_{i}, \tilde{r}_{j}} \sigma_{\tilde{r}_{i}} \sigma_{\tilde{r}_{j}}
$$

where $\rho_{\tilde{r}_{i}, \tilde{r}_{j}}$ denotes the correlation coefficient between the returns of asset class $i$ and $j$.

\section{The traffic light approach}

There are several ways to implement a solvency framework. The regulator could, for example, prescribe that each pension fund needs to set aside regulatory capital based on the outcome of a solvency test. Such an approach is common in the banking and insurance industries. In the case of occupational pension funds, however, which do not possess equity capital, this is rather problematic as the funds would need to build up reserves from contributions. On the other hand, pension funds have the possibility to demand additional contributions from employers and employees, which is similar to authorized equity capital of corporations that can be drawn in predefined cases. The risk of not being able to raise this capital when needed is negligible, since it resembles a tax levied by the government. Thus, we believe that the prescription of regulatory capital is not the most suitable approach for pension funds. Instead, our proposal is oriented towards early alert. For solvency measurement purposes, we combine the previously introduced pension fund model with a concept akin to a value-at-risk framework and funnel the results into a so-called traffic light approach. 
As discussed in the previous section, the model delivers a deterministic value for the liabilities at the end of the analysed period. Using this value as a threshold in conjunction with the asset distribution, we can derive shortfall probabilities for the pension fund under consideration. These probabilities could be compared to reference probabilities $\psi$, for example, default rates from rating agency data, in order to generate a signal for the regulator and the insured. Various categorisations for such a signal are conceivable. As a straightforward solution, we suggest the following:

- green:

$$
\operatorname{Pr}\left(\tilde{A}_{1} \leqslant L_{1}\right) \leqslant \psi
$$

- yellow:

$$
\operatorname{Pr}\left(\tilde{A}_{1}+A C_{1}^{\max } \leqslant L_{1}\right) \leqslant \psi
$$

- red:

$$
\operatorname{Pr}\left(\tilde{A}_{1}+A C_{1}^{\max } \leqslant L_{1}\right)>\psi
$$

where $A C_{1}^{\max }$ denotes the maximum amount of additional contributions which can be charged by the pension fund in $t=1 . A C_{1}^{\max }$ is deterministic, since it is based on the value of the liabilities in $t=1 .{ }^{35}$ If the probability of underfunded liabilities in $t=1$ is smaller than the preset reference probability $\psi$, the pension fund is assigned a green light. In addition, if the assets and the maximum additional contributions in $t=1$ are only insufficient to cover the liabilities with a probability lower than $\psi$, the light is yellow. In this case the fund is able to suppress the probability of underfunded liabilities in $t=1$ below the reference probability through its option of charging additional contributions. Finally, the red light comes up if the probability that the assets plus $A C_{1}^{\max }$ fall short of the liabilities exceeds $\psi$.

\section{Implementation and calibration}

\section{Input data}

A major advantage of the model is its low implementation cost due to the use of readily available data. In this section, we illustrate that even for smaller occupational pension funds with less sophisticated risk management techniques in place, it should be straightforward to calibrate and implement the model. For the purpose of calibration, we rely on accounting figures from the funds' annual reports. In practice, pension funds and regulators would be able to use superior data from their management accounting and financial planning units or databases. As such internal data is not available to us, we deem annual reports to be the most adequate and reliable source. Note that this approach is subject to certain limitations. As defined in the section "The

\footnotetext{
${ }^{35}$ Alternatively, different reference probabilities could be chosen for all three conditions.
} 
model framework", a solvency test for pension funds should theoretically be based on market values of assets and liabilities. This is in line with the latest developments in risk management practice as well as supervisory frameworks for the insurance sector (Solvency II and the SST). Yet, figures derived from annual reports are, in general, not consistent with market values. In particular, reported pension liabilities are commonly valued using a technical interest rate, that is, an actuarial rate instead of the prevailing term structure. Consequently, we substitute $i_{v}$ in Eq. (3) with the technical interest rate $i_{\text {tec }}$ applied by each fund. The appropriate level of the technical interest rate is currently controversially discussed in Switzerland. More specifically, some pension funds seem to be reluctant to reduce it so as to reflect the low interest rate environment which resulted from the financial crisis 2007/2008, implying an even greater discrepancy between market and book values of the liabilities. Nonetheless, we believe that the following numerical illustration of the proposed solvency framework offers useful insights.

Tables 1-4 show the parameter values we collected for ten occupational pension funds in Switzerland.$^{36}$ It is important to note that coverage ratios, assets, liabilities, technical interest rates and portfolio weights for 2007 and 2008 have been extracted from annual reports of the same year. In contrast to that, 2008 and 2009 figures have been used for contributions and benefits of 2007 and 2008, respectively, assuming that the funds can reliably forecast their values at the beginning of the period. ${ }^{37}$ Since the market values of the funds' assets could not be directly obtained from their annual reports, they have been estimated by multiplying the reported coverage ratios $\left(A_{0} / L_{0}\right)$ with the book values of the liabilities. Furthermore, we decided to conduct the analysis based on seven broad asset classes. Tables 3 and 4 contain the portfolio weights each fund assigns to these asset classes. ${ }^{38}$ Note that the asset allocation of some pension funds is fairly concentrated. The implications of this issue together with the effect of insufficient diversification within the subportfolio for each asset class will be addressed in the section "Concentration in asset class subportfolios". While the market environment in 2007 was still relatively stable, the 2008 figures reflect the major turbulences caused by the global financial crisis. Thus, this data set enables us to apply the solvency test in two different economic settings. In addition, we included single as well as multi-employer funds to further increase the informative value of our calculations.

It could be discussed whether the parameters for the asset class return distributions should be preset by the regulator, thereby reducing discretionary competencies to a minimum. However, taking into account the ease of estimation and regulatory verification of these parameter values, we suggest they should be determined by the pension funds themselves. Therefore, means, volatilities and pairwise correlations for the return distributions of the seven asset classes have been estimated from capital market time series data. To this end, we have chosen broad

\footnotetext{
${ }^{36}$ The funds were made anonymous.

${ }^{37}$ Our model treats these magnitudes as deterministic (see the section "The model framework"), thus assuming that they can be perfectly forecasted. If this is unlikely to be true, the model could be revised by incorporating benefits and contributions as stochastic variables.

${ }^{38}$ If deemed necessary, the solvency test could be based on a more detailed categorization of the asset side.
} 
Alexander Braun et al

Table 1 Input parameters for the sample funds in 2007

\begin{tabular}{lcrrrrrrrrr}
\hline Mil. CHF & Fund 1 & Fund 2 & Fund 3 & Fund 4 & Fund 5 & Fund 6 & Fund 7 & Fund 8 & Fund 9 & Fund 10 \\
\hline$A_{0} / L_{0}$ & $111 \%$ & $103 \%$ & $104 \%$ & $130 \%$ & $115 \%$ & $104 \%$ & $110 \%$ & $116 \%$ & $107 \%$ & $102 \%$ \\
$A_{0}$ & $11,591.90$ & $3,136.98$ & 247.65 & $14,585.39$ & $16,996.47$ & $1,173.10$ & $1,498.20$ & $6,582.35$ & $34,703.20$ & $13,589.43$ \\
$L_{0}$ & $10,415.01$ & $3,048.57$ & 237.67 & $11,176.54$ & $14,792.40$ & $1,130.16$ & $1,360.16$ & $5,688.67$ & $32,524.09$ & $13,309.92$ \\
$C_{0}$ & $1,175.49$ & 260.93 & 50.42 & 631.57 & 750.00 & 179.18 & 61.21 & $1,200.24$ & $1,360.62$ & 891.41 \\
$R C_{0}$ & 919.13 & 249.60 & 50.42 & 631.57 & 750.00 & 79.45 & 61.21 & $1,200.24$ & $1,183.44$ & 891.41 \\
$A C_{0}$ & 256.36 & 12.33 & 0.00 & 0.00 & 0.00 & 99.72 & 0.00 & 0.00 & 177.18 & 0.00 \\
$B_{0}$ & 787.37 & 201.88 & 15.58 & 837.47 & 797.20 & 87.57 & 90.87 & 711.13 & $2,359.56$ & 952.76 \\
$i_{\text {tec }}$ & $3.75 \%$ & $4.00 \%$ & $3.00 \%$ & $4.00 \%$ & $4.00 \%$ & $3.00 \%$ & $3.50 \%$ & $3.50 \%$ & $4.00 \%$ & $4.00 \%$ \\
\hline
\end{tabular}

Table 2 Input parameters for the sample funds in 2008

\begin{tabular}{|c|c|c|c|c|c|c|c|c|c|c|}
\hline Mil. CHF & Fund 1 & Fund 2 & Fund 3 & Fund 4 & Fund 5 & Fund 6 & Fund 7 & Fund 8 & Fund 9 & Fund 10 \\
\hline$A_{0} / L_{0}$ & $100 \%$ & $88 \%$ & $85 \%$ & $105 \%$ & $97 \%$ & $88 \%$ & $86 \%$ & $98 \%$ & $96 \%$ & $88 \%$ \\
\hline$A_{0}$ & $10,934.19$ & $2,866.88$ & 230.28 & $11,712.17$ & $14,822.70$ & $1,109.74$ & $1,174.94$ & $6,207.89$ & $30,290.15$ & $11,704.35$ \\
\hline$L_{0}$ & $10,923.27$ & $3,257.81$ & 270.60 & $11,186.41$ & $15,265.40$ & $1,261.07$ & $1,373.40$ & $6,317.17$ & $31,611.52$ & $13,285.30$ \\
\hline$C_{0}$ & 951.45 & 275.08 & 47.18 & 615.18 & 720.80 & 168.87 & 53.28 & $1,000.23$ & $1,357.44$ & 983.90 \\
\hline$R C_{0}$ & 937.62 & 261.17 & 47.18 & 615.18 & 720.80 & 106.50 & 48.56 & $1,000.23$ & $1,357.44$ & 983.90 \\
\hline$A C_{0}$ & 13.83 & 13.91 & 0.00 & 0.00 & 0.00 & 62.37 & 4.72 & 0.00 & 0.00 & 0.00 \\
\hline$B_{0}$ & 816.38 & 213.94 & 13.39 & 759.69 & 787.90 & 95.05 & 108.06 & 782.97 & $2,113.04$ & 882.45 \\
\hline$i_{t e c}$ & $3.75 \%$ & $4.00 \%$ & $3.50 \%$ & $4.00 \%$ & $4.00 \%$ & $3.00 \%$ & $3.50 \%$ & $3.50 \%$ & $3.50 \%$ & $3.50 \%$ \\
\hline
\end{tabular}

Table 3 Asset allocations of the sample funds in 2007

\begin{tabular}{lrrrrrrrrrr}
\hline$\%$ & Fund 1 & Fund 2 & Fund 3 & Fund 4 & Fund 5 & Fund 6 & Fund 7 & Fund 8 & Fund 9 & Fund 10 \\
\hline Bonds (intl.) & 9.7 & 14.4 & 33.5 & 13.2 & 18.3 & 23.0 & 8.9 & 12.3 & 23.5 & 15.3 \\
Bonds (CH) & 24.1 & 23.9 & 8.1 & 24.1 & 15.6 & 32.0 & 8.9 & 34.6 & 46.3 & 30.5 \\
Stocks (intl.) & 15.8 & 12.7 & 21.9 & 30.6 & 17.4 & 16.6 & 34.3 & 20.1 & 13.2 & 9.2 \\
Stocks (CH) & 4.4 & 19.0 & 6.2 & 7.8 & 11.2 & 13.6 & 5.5 & 15.9 & 7.3 & 18.3 \\
Real Estate & 11.4 & 15.4 & 6.5 & 9.0 & 23.8 & 2.5 & 25.0 & 12.7 & 5.4 & 10.3 \\
Alternatives & 9.7 & 4.0 & 10.3 & 12.5 & 4.3 & 6.9 & 7.7 & 2.2 & 0.0 & 8.1 \\
Cash & 25.0 & 10.7 & 13.4 & 2.9 & 9.4 & 5.4 & 9.6 & 2.2 & 4.3 & 8.4 \\
\hline
\end{tabular}

Table 4 Asset allocations of the sample funds in 2008

\begin{tabular}{lrrrrrrrrrr}
\hline$\%$ & Fund 1 & Fund 2 & Fund 3 & Fund 4 & Fund 5 & Fund 6 & Fund 7 & Fund 8 & Fund 9 & Fund 10 \\
\hline Bonds (intl.) & 9.2 & 15.8 & 15.0 & 22.4 & 5.2 & 22.7 & 6.4 & 13.5 & 19.4 & 18.5 \\
Bonds (CH) & 33.4 & 28.0 & 29.8 & 31.8 & 31.7 & 29.5 & 10.0 & 37.3 & 53.1 & 37.0 \\
Stocks (intl.) & 8.5 & 11.9 & 18.4 & 15.9 & 11.0 & 14.4 & 25.1 & 13.2 & 12.6 & 6.7 \\
Stocks (CH) & 2.4 & 13.4 & 5.1 & 3.7 & 9.2 & 12.5 & 5.1 & 11.7 & 6.9 & 13.5 \\
Real Estate & 10.8 & 16.6 & 7.8 & 9.1 & 28.1 & 7.4 & 30.5 & 14.8 & 6.1 & 10.5 \\
Alternatives & 17.1 & 2.4 & 7.7 & 10.2 & 4.5 & 9.2 & 7.5 & 4.7 & 0.0 & 8.3 \\
Cash & 18.6 & 11.9 & 16.4 & 6.9 & 10.2 & 4.4 & 15.4 & 4.7 & 2.0 & 5.6 \\
\hline
\end{tabular}


Table 5 Annualised means and standard deviations for the seven asset classes

\begin{tabular}{lccccccc}
\hline & $\begin{array}{c}\text { S\&P U.S. } \\
\text { Treasury } \\
\text { Bond Index }\end{array}$ & $\begin{array}{c}\text { SBI Swiss } \\
\text { Gov. Bond } \\
\text { Index }\end{array}$ & $\begin{array}{c}\text { MSCI } \\
\text { World }\end{array}$ & $\begin{array}{c}\text { SMI } \\
\text { Index }\end{array}$ & $\begin{array}{c}\text { Rued Blass } \\
\text { Swiss REIT } \\
\text { Index }\end{array}$ & $\begin{array}{c}\text { HFRI Fund } \\
\text { Weighted } \\
\text { Composite }\end{array}$ & $\begin{array}{c}\text { Swiss 3M } \\
\text { Money Mkt. } \\
\text { Index }\end{array}$ \\
\hline Currency denomination & USD & CHF & USD & CHF & CHF & USD & CHF \\
Mean return (\%) & 5.83 & 3.63 & 7.02 & 8.50 & 4.98 & 10.32 & 1.60 \\
Volatility (\%) & 3.71 & 3.51 & 14.04 & 17.22 & 7.67 & 7.19 & 0.29 \\
\hline
\end{tabular}

Table 6 Correlation matrix for the seven asset classes

\begin{tabular}{lccccccc}
\hline & $\begin{array}{c}\text { S\&P U.S. } \\
\text { Treasury } \\
\text { Bond Index }\end{array}$ & $\begin{array}{c}\text { SBI Swiss } \\
\text { Gov. Bond } \\
\text { Index }\end{array}$ & $\begin{array}{c}\text { MSCI } \\
\text { World }\end{array}$ & $\begin{array}{c}\text { SMI } \\
\text { Index }\end{array}$ & $\begin{array}{c}\text { Rued Blass } \\
\text { Swiss REIT } \\
\text { Index }\end{array}$ & $\begin{array}{c}\text { HFRI Fund } \\
\text { Weighted } \\
\text { Composite }\end{array}$ & $\begin{array}{c}\text { Swiss 3M } \\
\text { Money Mkt. } \\
\text { Index }\end{array}$ \\
\hline S\&P U.S. Treasury Bond Index & 1.00 & & & & & & \\
SBI Swiss Gov. Bond Index & 0.57 & 1.00 & & & & & \\
MSCI World & -0.27 & -0.22 & 1.00 & & & & \\
SMI Index & -0.30 & -0.17 & 0.74 & 1.00 & & \\
Rued Blass Swiss REIT Index & 0.00 & 0.21 & 0.27 & 0.26 & 1.00 & & 1.00 \\
HFRI Fund Weighted Composite & -0.19 & -0.16 & 0.77 & 0.50 & 0.22 & -0.14 & 1.00 \\
Swiss 3M Money Mkt. Index & 0.21 & 0.12 & -0.21 & -0.14 & -0.07 & -0.14 \\
\hline
\end{tabular}

indices as representatives for each asset class. ${ }^{39}$ The S\&P U.S. Treasury Bond Index and the SBI Swiss Government Bond Index have been selected as proxies for the international and Swiss government bond markets, respectively. International equities are represented by the MSCI World, while the Swiss Market Index (SMI) is employed for the Swiss equity market. Real estate returns are provided through the Rued Blass Swiss REIT Index and the HFRI Fund Weighted Composite Index serves as a broad measure for the alternative investments universe. Finally, the Swiss 3M Money Market Index is used as an indicator for the development of cash holdings. Distribution moments as well as a correlation matrix based on monthly returns for these indices from 1 January 1997 to 31 December 2007 are exhibited in Tables 5 and 6 . Based on the simplifying assumption that the pension funds can perfectly hedge exchange rate fluctuations at a negligible cost, we have not converted the time series of the three U.S. dollar-denominated indices into Swiss francs. Since hedging foreign currency investments against exchange rate risk is very common $^{40}$ in the asset management industry and the trading costs for the necessary foreign exchange $(\mathrm{FX})$ instruments such as futures and options are relatively small, ${ }^{41}$

${ }^{39}$ Wherever available, total return indices have been used to account for coupons and dividends.

${ }^{40}$ As an example, consider an investment in a foreign currency-denominated government bond. If left completely unhedged, this would be an outright speculation on the exchange rate, as the returns in the investor's home currency will be dominated by exchange rate movements, implying that the asset does not exhibit the typical characteristics of a government bond.

${ }^{41}$ Flat fees for FX futures trades at the Chicago Mercantile Exchange (CME), the largest regulated FX marketplace worldwide, can be as low as 0.11 USD, depending on membership and volume. For more information see www.cmegroup.com. 
we believe this to be an acceptable approach for our purpose. The effect of imperfect FX hedging will be considered in the section "Exchange rate risk".

\section{Results}

In order to be able to interpret the shortfall probabilities with the traffic light approach presented in the previous section, we need to determine reference probabilities. A straightforward approach is to refer to historic default rate data as commonly collected and maintained by the large rating agencies. Consequently, we suggest constructing probability intervals for rating categories based on default rate experience. The regulator could then set a minimum target rating for occupational pension funds, which is linked to the threshold probability.

In the following we use global corporate cumulative default rates from 1981 to 2008 provided by Standard \& Poor's ${ }^{42}$ and establish intervals for the one-year default probabilities as shown in Table $7 .{ }^{43}$ As a reasonable minimum target rating for pension funds, we propose the lowest investment grade rating category: BBB. As discussed in the section "The particularities of the Swiss occupational pension fund system", participation in the occupational pension fund system in Switzerland is not voluntary. In addition, the volume invested through contributions of employers and employees is significant. As a result, occupational pension funds bear much responsibility for an individual's retirement provisions. Against this background, their financial strength should be demanded to be investment grade. Otherwise the uncertainty for those insured would be considerable, while they are not free to entrust their money with other financial institutions of their choice. Moreover, from the perspective of regulators and financial market participants, it would be very difficult to argue why pension funds should be allowed a notably lower credit quality than other financial institutions such as banks or insurance companies.

Having determined the reference probability $\psi$ to be 0.99 per cent (upper bound of BBB), we can now run the model calculations and interpret the results. For each fund, the probabilities for the traffic light conditions in 2007 and 2008 as well as the associated test outcomes (pass/fail) are presented in Tables 8 and 9, respectively. The calculations for the yellow condition have been conducted based on a $\beta$ of 0.95 and 0.90 , that is, we limited the maximum additional contributions per period to 5 and 10 per cent of the liabilities. ${ }^{44}$ First, we observe that four out of ten funds fail the green condition in 2007, although none has underfunded liabilities at the outset (the lowest coverage ratio among the sample funds in 2007 was 102 per cent, see Table 1). When inspecting the coverage ratio these four funds actually reported in 2008 (see Table 2), we find that all of them in fact suffer from underfunded liabilities, ranging from 2 to an alarming 15 per cent. A fund with a 15 per cent deficit of assets relative to liabilities

\footnotetext{
${ }^{42}$ See Standard \& Poor's (2009).

${ }^{43}$ While the use of specific default rates for the investment industry in general or the pension fund market segment in particular would be preferable, we need to rely on the rather high-level data available to us. Nevertheless, in case of an introduction in practice, it would be advisable for the regulator to cooperate with rating agencies in order to access a more precise database.

${ }^{44}$ Recall the definition of $\beta$ from Eq. (9). As discussed, it is ultimately up to the regulator to set a value for $\beta$.
} 
Table 7 One-year default probabilities for different rating classes (see Standard \& Poor's, 2009)

\begin{tabular}{lcccccr}
\hline$\%$ & $A A A$ & $A A$ & $A$ & $B B B$ & $B B$ & \multicolumn{1}{c}{$B$} \\
\hline Lower bound & 0.00 & 0.03 & 0.08 & 0.24 & 0.99 & 4.51 \\
Upper bound & 0.03 & 0.08 & 0.24 & 0.99 & 4.51 & 25.67 \\
\hline
\end{tabular}

Table 8 Probabilities and test outcomes for the traffic light conditions in 2007

\begin{tabular}{|c|c|c|c|c|c|c|c|c|c|c|}
\hline$\%$ & Fund 1 & Fund 2 & Fund 3 & Fund 4 & Fund 5 & Fund 6 & Fund 7 & Fund 8 & Fund 9 & Fund 10 \\
\hline \multirow[t]{2}{*}{ Green condition } & 0.01 & 18.36 & 7.29 & 0.00 & 0.10 & 0.07 & 3.28 & 0.24 & 0.70 & 21.42 \\
\hline & Pass & Fail & Fail & Pass & Pass & Pass & Fail & Pass & Pass & Fail \\
\hline \multirow{2}{*}{$\begin{array}{l}\text { Yellow condition } \\
\beta=0.95\end{array}$} & 0.00 & 3.02 & 0.47 & 0.00 & 0.00 & 0.00 & 0.45 & 0.01 & 0.00 & 3.06 \\
\hline & Pass & Fail & Pass & Pass & Pass & Pass & Pass & Pass & Pass & Fail \\
\hline \multirow{2}{*}{$\begin{array}{l}\text { Yellow condition } \\
\beta=0.90\end{array}$} & 0.00 & 0.18 & 0.01 & 0.00 & 0.00 & 0.00 & 0.03 & 0.00 & 0.00 & 0.13 \\
\hline & Pass & Pass & Pass & Pass & Pass & Pass & Pass & Pass & Pass & Pass \\
\hline
\end{tabular}

Table 9 Probabilities and test outcomes for the traffic light conditions in 2008

\begin{tabular}{lccccccccccc}
\hline$\%$ & Fund 1 & Fund 2 & Fund 3 & Fund 4 & Fund 5 & Fund 6 & Fund 7 & Fund 8 & Fund 9 & Fund 10 \\
\hline $\begin{array}{l}\text { Green condition } \\
\text { Fail }\end{array}$ & $\begin{array}{c}29.46 \\
\text { Fail }\end{array}$ & $\begin{array}{c}99.44 \\
\text { Fail }\end{array}$ & $\begin{array}{c}\text { Fail } \\
\text { Fail }\end{array}$ & $\begin{array}{c}\text { Fail } \\
\text { Fail }\end{array}$ & $\begin{array}{c}\text { Fail } \\
\text { Fail }\end{array}$ & $\begin{array}{c}\text { Fail } \\
\text { Fail }\end{array}$ \\
$\begin{array}{l}\text { Yellow condition } \\
\beta=0.95\end{array}$ & 1.23 & 91.07 & 97.74 & 0.09 & 23.06 & 43.52 & 94.09 & 10.94 & 26.29 & 92.20 \\
Fail & Fail & Fail & Pass & Fail & Fail & Fail & Fail & Fail & Fail \\
$\begin{array}{l}\text { Yellow condition } \\
\beta=0.90\end{array}$ & 0.00 & 53.69 & 72.41 & 0.00 & 2.41 & 8.34 & 72.87 & 0.65 & 1.19 & 50.28 \\
\hline & Pass & Fail & Fail & Pass & Fail & Fail & Fail & Pass & Fail & Fail \\
\hline
\end{tabular}

is in a serious state, since, even for the lower $\beta$ of 0.90 , it cannot be restructured through additional contributions in a single period. Taking into account that the current convention in Switzerland is a maximum of five years to eliminate the deficit, the fund needs additional contributions of at least 3 per cent per year. These are already close to the 5 per cent upper limit which we applied in the analyses for the yellow condition, underscoring the severity of this situation. Hence, a failure of the green condition is only acceptable in exceptional cases and should instantly trigger heightened attention from the supervisor as well as those insured. In this context it should also be emphasised that a need for refinements to the traffic light approach is not automatically constituted by the fact that Fund 3 ends up with a deficit in excess of $A C_{1}^{\max }$ in 2008 , although it was assigned a yellow light in the previous period. The proposed solvency test is exclusively based on probabilities. Therefore, by all means, a fund can pass one or both traffic light conditions and still end up with substantial unfunded liability at the end of the period. Being assigned a green or yellow light only 
means that the probability for the respective event is sufficiently low. However, if similar discrepancies are detected for a large number of funds in the context of a comprehensive quantitative impact study prior to the introduction of the solvency test, its overall configuration and calibration should be reconsidered.

The second point we learn from Table 8 is that a $\beta$ of 0.95 is more than enough to compress the probabilities for the yellow condition to very low levels for almost all funds. Evidently, this effect is even stronger for $\beta=0.90$. While the probabilities are virtually zero for the financially sounder pension funds, even those which did not conform to the green condition seem to be able to comply with the yellow condition without difficulties. This illustrates an important point, which had already been mentioned in the section "The traffic light approach": the option to demand additional contributions implies that a large part of the pension funds' investment risk is ultimately borne by employees and employers. Consequently, in case of an actual introduction of the proposed approach in practice, the supervisory authority should carefully determine the upper limit on additional contributions.

A further insight we gain from the analysis is that merely comparing the coverage ratios, as currently done in supervisory practice in Switzerland, is generally insufficient to capture the risk profile of pension funds. To see this, compare Fund 3 and Fund 6. Both are characterised by an equal coverage ratio of 104 per cent in 2007 (see Table 1). However, only Fund 6 passes the green condition of our proposed solvency test (see Table 8). The reason is simple: a comparison of the coverage ratio does not take into account differences in asset allocation and the option to charge additional contributions.

Finally, when examining the results of the solvency test for 2008 in Table 9, we notice that the financial crisis has strongly influenced the condition of the pension funds in our sample. Since all funds except Fund 1 and Fund 4 already exhibit underfundings at the beginning of the period (see Table 2), their probabilities for both the green and yellow condition have increased considerably. As a result, not a single pension fund is able to pass the green condition and only one (Fund 4) passes the yellow condition based on a $\beta$ of 0.95 . Although the analysed sample is rather small, this illustrates that the financial crisis has left the Swiss pension fund sector in a dramatic situation.

\section{Sensitivity analysis}

In this section, we explore the main drivers of the shortfall probabilities for the traffic light approach. These are relevant for the regulator in various ways, including the political discussion about the state of the Swiss occupational pension fund sector, the supervisory determination of model variables, and the decision about measures in case a pension fund fails the green or yellow condition of the solvency test. We base the analysis on a standard (representative) pension fund, the input data for which can be found in Table 10. ${ }^{45}$ This data is mainly based on 2007 average figures from the Swisscanto pension fund survey, ${ }^{46}$ comprising 265 occupational pension funds in

\footnotetext{
${ }^{45}$ Unless noted otherwise, $\beta$ has been set to 0.95 .

${ }^{46}$ See Swisscanto (2008).
} 
Table 10 Parameters for a representative pension fund

\begin{tabular}{lrlr}
\hline & Input & & Asset allocation (\%) \\
\hline$A_{0} / L_{0}$ & $110 \%$ & Bonds (intl.) & 13 \\
$A_{0}$ & 11,000 & Bonds (CH) & 27 \\
$L_{0}$ & 10,000 & Stocks (intl.) & 18 \\
$C_{0}$ & 1,000 & Stocks (CH) & 10 \\
$R C_{0}$ & 1,000 & Real Estate & 15 \\
$A C_{0}$ & & Alternatives & 7 \\
$B_{0}$ & 750 & Cash & 10 \\
$i_{\text {tec }}$ & $4 \%$ & & \\
\hline
\end{tabular}

Switzerland, and has been complemented and cross-checked with annual report data from our sample. ${ }^{47}$ The standard pension fund under consideration is financially sound at the beginning of the period with a coverage ratio of 110 per cent and a fairly balanced asset allocation.

\section{Portfolio weight allocated to equities}

The first sensitivity we examine is related to the proportion of equities in the pension fund's portfolio. In this context we proceed as follows: from the original asset allocation in Table 10, we calculate the weight of each asset class with regard to the remaining part of the portfolio if stocks (international and Swiss) are excluded. As an example, consider the category alternative investments: aside from stocks, the remaining asset classes together make up 72 per cent of the portfolio, 7 per cent of which are alternative investments. Consequently, alternative investments are assigned a "residual" weight of $7 / 72=9.7$ per cent for the analysis. In the same fashion, we get 18.1 per cent for international bonds, 37.5 per cent for Swiss bonds, 20.8 per cent for real estate, 9.7 per cent for alternatives and 13.9 per cent for cash. We then successively calculate the shortfall probabilities associated with the traffic light conditions for an increasing portfolio weight of stocks, beginning with zero and ending with the legal limit of 50 per cent. In every case, the percentage is equally shared between Swiss and international equities. For each allocation, the remainder of the portfolio is distributed among the other asset classes according to the previously calculated residual weights. Figure 1 shows the results.

As one would expect, the shortfall probabilities generally increase in the portfolio weight assigned to equities. The probabilities associated with the pension fund's original portfolio composition as shown in Table 10 are represented through a point and a triangle on the curves at the 0.28 position, ${ }^{48}$ while the threshold probability of 0.99 per cent has been indicated by the dotted horizontal line. In its current state this

\footnotetext{
${ }^{47}$ The Swisscanto series of surveys is published on an annual basis and contains representative data with regard to the structure, performance, capitalization and portfolio allocation of the participating funds.

${ }^{48}$ Note that these points are in fact slightly off the curve since at the position 0.28 the curve has been calculated with 0.14 allocated to international and 0.14 allocated to Swiss stocks, while the original asset allocation shows 0.18 and 0.10 , respectively.
} 


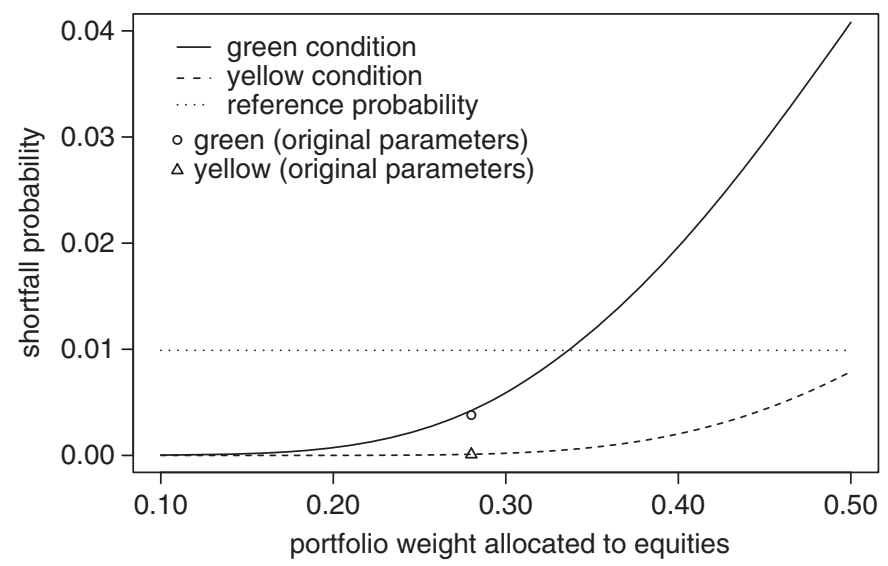

Figure 1. Sensitivity analysis: asset allocation.

average pension fund evidently passes the green condition with ease. On the one hand, we observe that the increase of the probability curve for the green condition is quite strong, revealing a critical portfolio weight for equities of 0.34 , that is, well below the legal limit of 0.50 . On the other hand, Figure 1 reveals that the fund would in no case fail the yellow condition, even for the highest possible allocation to stocks. Hence, as already suspected in the previous section, allowing additional contributions up to 5 per cent of the liabilities within a single year bears a considerable potential to suppress the shortfall probabilities. These results have an important implication for the regulator. One of the prevalent regulatory actions in case of a failure of the green traffic light condition should be an in-depth analysis of the portfolio composition of the respective pension fund with a focus on the more volatile asset classes such as equities. This could be followed by a dialogue between the fund and the regulator to agree on an optimisation of the portfolio to lower the probability of failing the green condition while still retaining reasonable return potential.

\section{Concentration in asset class subportfolios}

In the section "Input data" we calibrated the model based on indices (well-diversified portfolios), representing various asset classes. This approach implicitly assumes that pension funds adequately diversify their investments within the subportfolio of each asset class. In practice, a basic degree of diversification should be ensured, since pension funds have to obey mandatory limits on their asset positions. The equity portfolio, for example, cannot account for more than 50 per cent of a fund's total assets. In addition, within this equity portfolio, the maximum investment per individual stock (domestic or international) is currently limited to 5 per cent of the total assets. Yet, with its calibration relying on indices, the solvency test might not be well suited for an application to pension funds which hold insufficiently diversified subportfolios. Thus, we briefly illustrate the impact of concentration issues within subportfolios, using domestic equity holdings as an example. For this purpose, we 


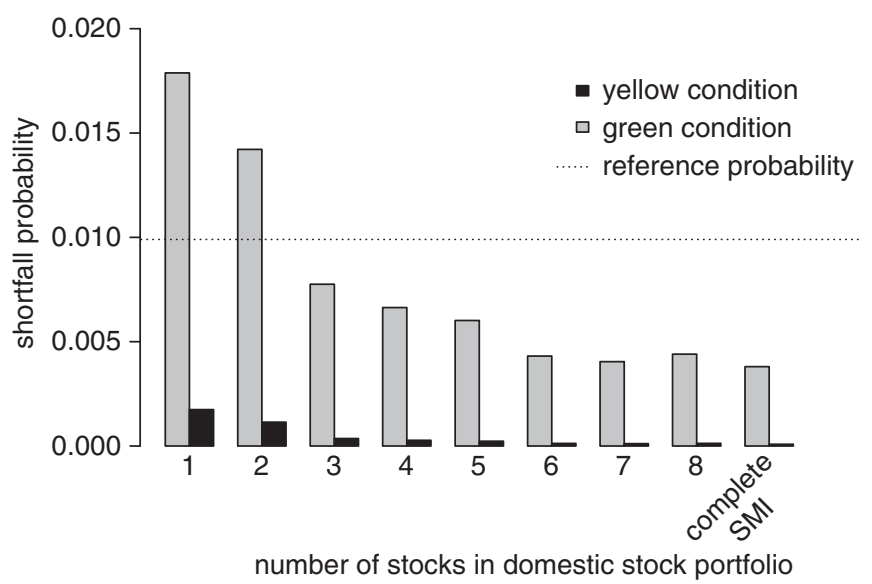

Figure 2. Sensitivity analysis: asset concentration in the domestic stock portfolio.

form an equally weighted portfolio (naïve diversification), consisting of an increasing number of stocks which are drawn from the constituents of the SMI Index. First, the portfolio only contains a single stock. Additional stocks are then successively added in random order until the portfolio contains a total of eight stocks. ${ }^{49}$ For each step, we recalculate mean and volatility of the domestic equity portfolio (Table 5, column 4) as well as the correlations with the other asset classes (Table 6, line 4 and column 4) and recalibrate the model accordingly. The resulting shortfall probabilities for the solvency test are illustrated in Figure 2, together with the original case based on the complete SMI (20 stocks). As expected, the shortfall probabilities tend to decrease with a rising number of equally weighted stock holdings in the portfolio, that is, with a decreasing asset concentration. ${ }^{50}$ More specifically, for the relatively small number of six equities in the portfolio, the shortfall probabilities are already fairly close to those of the original case with the SMI as domestic equity portfolio. Therefore, only very high degrees of asset concentration in the subportfolios should result in a notable distortion of the proposed solvency test. However, if a pension fund naïvely diversifies its holdings over at least half a dozen stocks, the use of indices for calibration purposes seems to be a valid approach. To further underscore this, note that the standard pension fund underlying the sensitivity analyses in this section has a total of 18 (international $)+10($ domestic $)=28$ per cent invested in equities (see Table 10). Taking into account the legal limit of 5 per cent per individual stock, this implies that the fund needs to have at least $28 / 5=5.6 \approx 6$ different stocks in its portfolio. Similarly, consider a hypothetical pension fund which invested the legal maximum of 50 per cent of its

49 The final portfolio consists of the following equities, mentioned in the sequence in which they have been added: Credit Suisse Group, Adecco SA, Roche Holding AG, Holcim Ltd., SGS SA, Nestle SA, Swatch Group AG and Swiss Re.

${ }^{50}$ Note that while we observe a general decrease in the shortfall probability for a growing number of stocks in the portfolio, it can sometimes slightly increase when a new stock is added, depending on the order of inclusion. This effect occurs due to changes on the overall correlation structure in the portfolio. 
portfolio in equities. As a result, its equity holdings would need to consist of a minimum of $50 / 5=10$ different stocks. Nevertheless, if for some reason a subportfolio is extremely concentrated, the model should be recalibrated accordingly.

\section{Misestimation of liabilities}

Another interesting question centres around the valuation of liabilities. As explained in the previous two sections, the model at the heart of our approach to measuring pension fund solvency treats the liabilities as deterministic and relies on input figures which are reported by the pension funds themselves. A current discussion in the Swiss pension fund system revolves around the technical interest rate, which serves as a discount rate for the stochastic future cash outflows in the context of an actuarial valuation of the liabilities. It has repeatedly been stated that many funds hesitated to lower their technical interest rate in lockstep with the development of the term structure, thereby understating the present value of their technical liabilities. ${ }^{51}$ In addition, despite various hedging techniques broadly applied in practice, ${ }^{52}$ there is a remaining uncertainty about future mortality improvements and their modeling. Obviously, a potential misestimation of the liabilities will have consequences for the results of the proposed solvency test. Thus, Figure 3 displays the sensitivity of the shortfall probabilities with regard to the estimation error of the technical liabilities. ${ }^{53}$ We observe a pattern similar to the effect of a change in the portfolio weight of stocks examined in the section "Portfolio weights allocated to equities". Again, the graph comprises a point and a triangle, representing the shortfall probabilities for the original value of the liabilities. In the area to the left of these points, where the liabilities are found to have been overestimated, the actual shortfall probabilities rapidly decline towards zero. The opposite is true for an underestimation, however. If the liabilities were a mere 1.6 per cent higher than originally estimated, the fund would already breach the threshold for the green condition. Beyond that estimation error, the increase of the probabilities becomes even steeper. Again, the whole curve for the yellow condition lies below the reference probability. A practical insight associated with these results is that the supervisory review should include an in-depth analysis of the methodology, assumptions and database which the pension funds employ to estimate their liabilities. In case the supervisor has reasons to doubt the precision of the estimates, the outcome of the solvency test would have to be adjusted.

\section{Coverage ratio}

Next, we consider the probabilities' sensitivity to the coverage ratio of the pension fund at the beginning of the period. Figure 4 shows the results for coverage ratios varying from 1.10 down to 0.85 . Again, the values of 0.3803 per cent for the green condition and 0.0085 per cent for the yellow condition associated with the original

\footnotetext{
${ }^{51}$ See, for example, Swisscanto (2008).

52 See, for example, Mao et al. (2008), Yang and Huang (2009).

${ }^{53}$ The estimation error is defined as true minus estimated value of liabilities.
} 


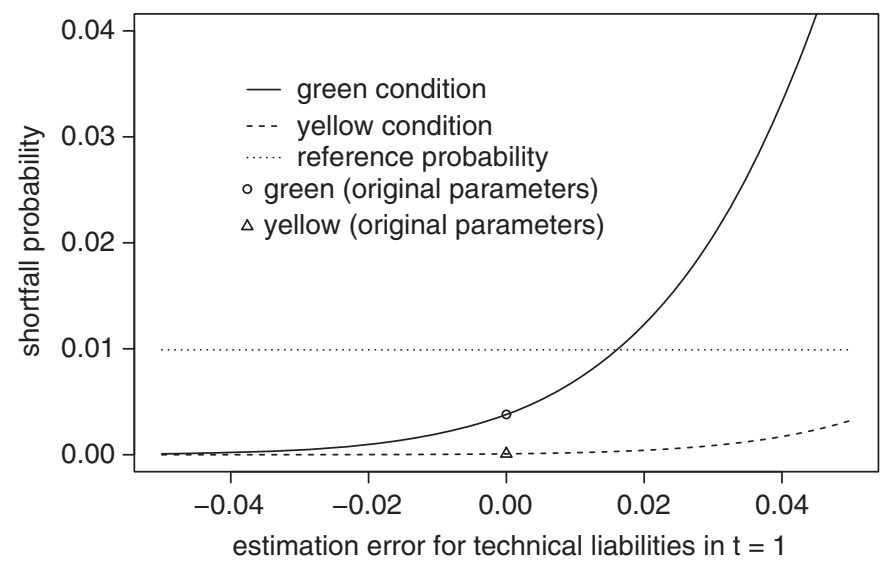

Figure 3. Sensitivity analysis: liabilities.

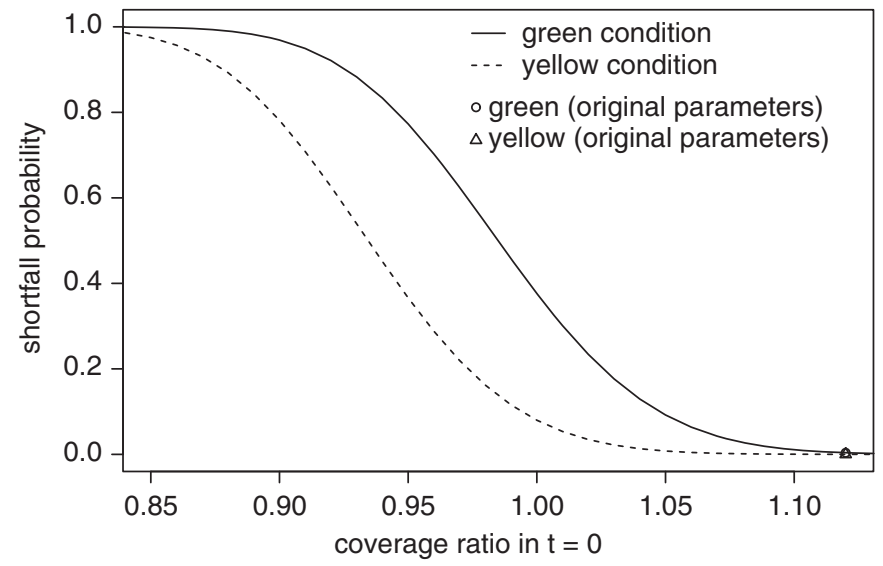

Figure 4. Sensitivity analysis: coverage ratio.

coverage ratio of 1.10 (see Table 10) are represented by a point and a triangle on the curves. ${ }^{54}$ The results for coverage ratios over and above 1.10 are not particularly interesting as the shortfall probabilities quickly become very small. Similarly, we observe that for coverage ratios of below 0.90 , the probabilities are very close to one and thus far beyond any reasonable threshold. Some more attention should be devoted to the region between 0.90 and 1.10 . Just below 1.10 , both curves initially exhibit a slightly negative slope, which then sharply increases in magnitude below 1.05 for the curve representing the green and below 1.00 for the curve representing the yellow

\footnotetext{
${ }^{54}$ Owing to their small difference relative to the scale chosen for the overall graph, these points appear as one.
} 
condition. Hence, pension funds with a coverage ratio of below 1.05 are relatively likely to end up with underfunded liabilities at the end of the period. In addition, if their liabilities are just about covered at the beginning of the period, even the probability for failing the yellow condition grows to levels where it begins to be perceivable. This has important implications for the Swiss occupational pension fund system. In particular, the common practice of letting pension funds continue their business with dramatically underfunded liabilities without a specifically tight supervisory review and careful amendments to their overall strategy has to be considered inadequate from the point of view of modern risk management and solvency regulation principles.

\section{Lowest acceptable coverage ratio}

Furthermore, we examine the sensitivity of the shortfall probability for the yellow condition with regard to $\beta$, that is, the lowest coverage ratio acceptable by the supervisor. The results are depicted in Figure 5. Consistent with our previous analyses, the curve begins at a $\beta$ of 0.95 which is associated with a near zero probability $(0.0085$ per cent) of an underfunding after additional contributions (marked by a triangle). For an increasing $\beta$, however, we observe a non-linear rise in the probability. A $\beta$ of 0.97 , for example, is already associated with a probability of 0.0460 per cent, which is more than five times the above value. When $\beta$ approaches 1 , that is, additional contributions are ruled out, the probability reaches the value of 0.3803 per cent associated with the green condition (marked by a point). This suggests that the impact of each percentage of additional contributions allowed to fix deficits is relatively strong.

Since both the current and lowest acceptable coverage ratio have a strong influence on the shortfall probability for the yellow condition, we finally want to consider their joint impact in order to assess which combinations have counterbalancing or strengthening effects (see Figure 6). A very important observation is that for $\beta$ below approximately 0.96 , the yellow condition becomes rapidly less binding, even if we assume that the fund already begins the period with a relatively weak coverage ratio of

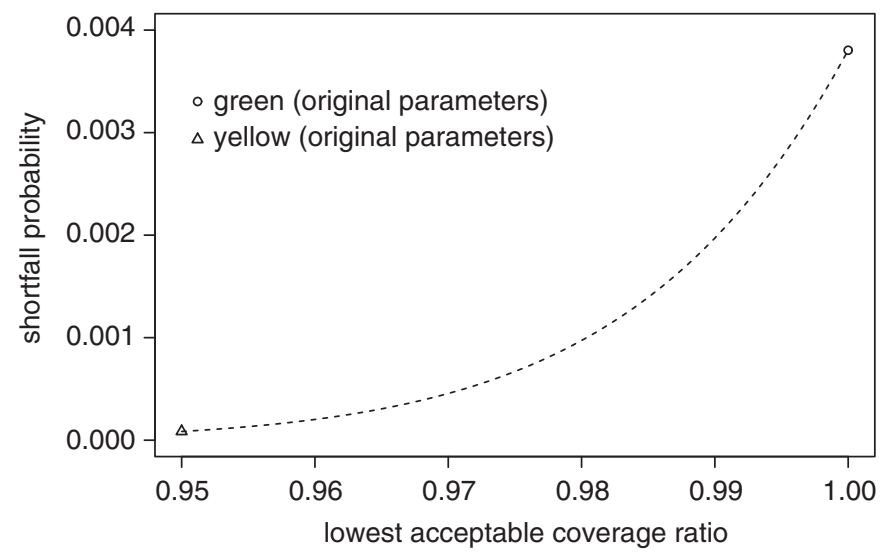

Figure 5. Sensitivity analysis: lowest coverage ratio acceptable by the supervisor. 


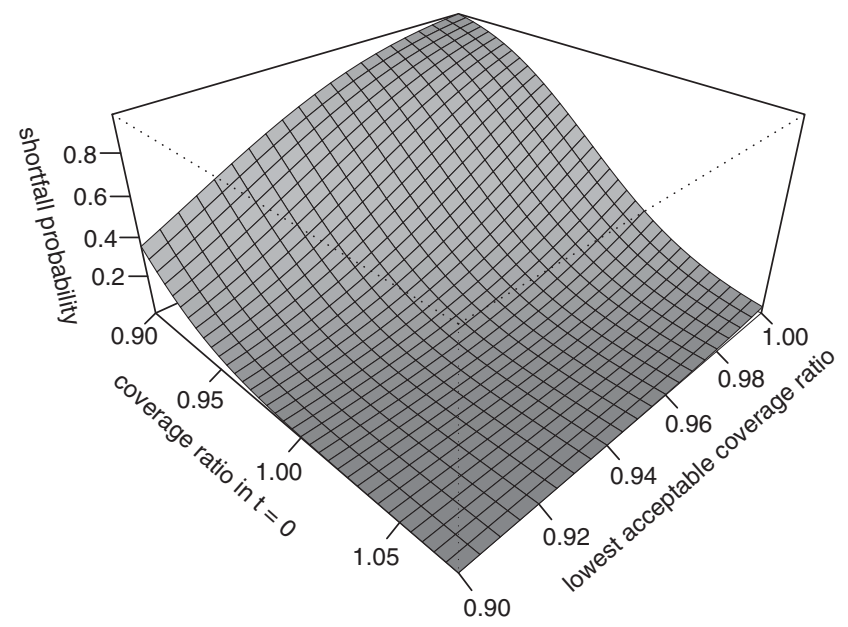

Figure 6. Sensitivity analysis: actual and lowest acceptable coverage ratio (yellow condition).

around 1 . For a $\beta$ of 0.90 , the shortfall probability for condition yellow is virtually negligible until the coverage reaches 0.95 where it begins to rise sharply. In contrast, if $\beta$ is set to 1 (no additional contributions allowed), even a relatively small underfunding leads to large shortfall probabilities, which reach 100 per cent around the coverage ratio of 0.90 . Thus, as previously suspected, the regulator's choice of $\beta$ has a crucial impact on the bindingness of the yellow traffic light condition. Simply allowing pension funds with a low coverage ratio to draw on large amount of additional contributions per period provides them with a convenient means to continue business without significant revisions to their asset or risk management practices. This somewhat contradicts the purpose of a solvency test and essentially means that premium payers subsidise pensioners, an effect which is generally not intended within the second pillar of the Swiss pension system.

\section{Exchange rate risk}

In the section "Input data", we mentioned that the U.S. dollar-denominated indices have not been converted to Swiss francs for the model calibration. For this to be an adequate approach, pension funds would need to hedge out major exchange rate fluctuations in their asset portfolios at an immaterial cost. In this section, we relax the assumption of a perfectly FX hedged portfolio and analyse the impact of exchange rate risk on the shortfall probabilities. To this end, we convert the time series of the three U.S. dollardenominated indices ${ }^{55}$ to Swiss francs and compute the associated returns. For each index, we then calculate weighted averages of the returns of the original time series (U.S. dollars) and the returns of the converted time series (Swiss francs), applying weights

\footnotetext{
${ }^{55}$ These are the S\&P U.S. Treasury Bond Index, the MSCI World and the HFRI Fund Weighted Index. See Table 5 .
} 


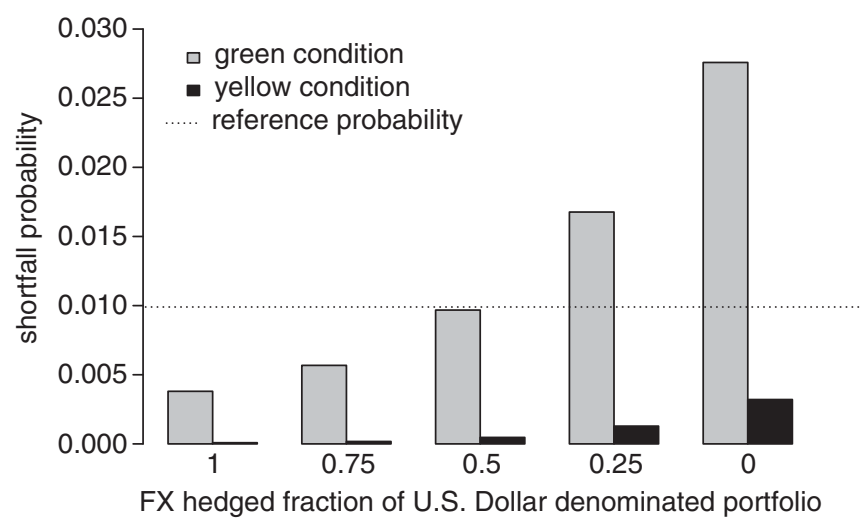

Figure 7. Sensitivity analysis: FX hedging of the U.S. dollar-denominated portfolio.

of $100,75,50,25$ and 0 per cent. These weights are meant to reflect the percentage of the foreign currency-denominated portfolio which has been hedged against exchange rate risk. $^{56}$ Accordingly, a 100 per cent weight on the returns of the U.S. dollar index time series reflects a situation where the whole portfolio is immune to exchange rate fluctuations, whereas a 100 per cent weight on the returns of the Swiss franc converted time series implies no FX hedging activity at all. For all combinations in between, the exchange rate risk is assumed to be partially hedged. Subsequently, means, volatilities, correlation matrix and the resulting shortfall probabilities are recalculated for each case. For both the green and yellow condition the shortfall probabilities expectedly rise with the exchange rate exposure (see Figure 7). If foreign investments in the pension fund's portfolio remain entirely unhedged, the probability for the green condition turns out to be more than seven times higher than in the case of a perfect FX hedge. However, we also see that the pension fund would still be assigned a green light if it protects only half of its foreign asset holdings against exchange rate risk. In addition, the yellow condition is passed in every case, even without any FX hedging activities. From these insights we conclude that a model calibration based on foreign currency-denominated indices should be valid, as long as pension funds hedge a large part of their foreign asset portfolio against exchange rate fluctuations. If this is not the case, a model recalibration should be requested and monitored by the supervisory authority.

\section{Supervisory review and actions}

In analogy to Basel II and the SST, the approach we introduced and illustrated throughout the previous sections should be embedded into a comprehensive supervisory review process. As part of this process, occupational pension funds

\footnotetext{
${ }^{56}$ While this is a rather general analysis, abstracting from a detailed characterisation of the associated transactions with regard to strategy, timing, instruments, volumes, strike prices, etc., we believe it to be satisfactory in this context. A more elaborate treatment of FX hedging issues in the asset management industry is beyond the scope of this paper.
} 
should be obliged to report and comment on certain key figures resulting from the application of the supervisory model in regular intervals. This quantitative solvency report could be accompanied by a qualitative judgement of risks which are not explicitly covered by the model framework, such as credit and operational risk.

In order to react properly to the risk and solvency situation of pension funds, the regulator should possess a variety of competencies. According to the degree of compliance with the traffic light conditions, a certain catalogue of measures could be decided. For pension funds which are assigned a green light, the regulator could stick to periodic reviews focused on the adequacy of the regulatory standard model. As illustrated in the section "Concentration in asset class subportfolios", a recalibration could become necessary in certain cases.

If a pension fund hands in a regulatory report with a yellow light, it should be subjected to closer scrutiny. This could, for instance, comprise a comprehensive checkup of the fund's assets, liabilities, liquidity and cash flow profile with a particular focus on valuation methodologies and assumptions. In addition, such funds could be put on a regulatory watch list, resulting in a shortened reporting interval. The requirement to design a concept for financial restructuring is also a potential measure to be imposed on funds in the yellow category. Such a concept would need to cover the asset and liability side, demonstrating how a solid solvency situation can be restored through a combination of portfolio adjustments as well as capital replenishment by means of additional contributions. In any case, the regulator would have to ensure that the lower and upper limit for additional contributions is obeyed.

If a fund is assigned a red light, more drastic consequences would be necessary. These could comprise constraints to the management's ability to choose its asset allocation with the aim of preventing the fund from incurring additional investment risks. Otherwise the problem of "gambling for resurrection" could arise, meaning that the fund management tries to rescue the institution through large bets. Furthermore, the regulator should be authorised to issue directives to the management of red light funds. Moreover, the admission of additional contributors should be suspended until the fund has been restored to an acceptable level of solvency. This protects prospective fund members from the excessive subsidization of current pensions through their contributions. Finally, the regulator should have the ability to replace the board and fund management of highly distressed pension funds with a special administrator.

Beyond that, rules with regard to the publication and dispersion of these easily interpretable solvency signals could increase transparency, and, given the receivers, can appropriately react to the information, and promote market discipline. Hence, apart from the supervisory authority, receivers of the signal should be employers, employees, transaction partners and the general public. Owing to a reduction of information asymmetries, pension funds with an abnormally high shortfall probability would thus have to face public scrutiny and reactions of their business partners.

\section{Some notes on a potential introduction in Switzerland}

An important organisational requirement for pension funds which would arise from a concrete introduction of the solvency test is the recruitment of personnel with an 
adequate background for the application and maintenance of stochastic pension fund models. Further requirements relate to the necessary infrastructure for running the model, including databases and software. In order to align the fund manager's interest with that of the insured, the former should benefit from the prevention of yellow signals. This could, for example, be achieved by linking his variable compensation to a combination of fund performance and traffic light signals.

As explained in the section "The particularities of the Swiss occupational pension fund system", Swiss occupational pension funds take the legal form of private trusts, which have very limited possibilities of self-supervision. A corporation, in contrast, has bodies such as the board and annual meeting, which serve supervisory purposes. Consequently, the introduction of a regulatory framework for occupational pension funds could be complemented with a fundamental reformation of the legal forms they can adopt. The recommended traffic light approach would then receive additional disciplinary weight through the board and shareholders of the corporation as receivers of the signal.

The degree of market discipline emanating from the traffic light approach strongly depends on its familiarity to stakeholder groups and the expected consequences of bad signals such as the potential threat of many insureds wanting to change their pension fund. However, employees are currently not free in their choice, which greatly reduces this sort of pressure. Therefore it needs to be discussed whether the introduction of the solvency regulation should be accompanied by a liberalization of the market itself, enabling a free choice of the pension fund. The downside would be that the situation of an already distressed fund could further deteriorate in case a large number of insureds wants to redeem their holdings. Nevertheless, we believe that more flexibility in this regard is warranted and would be an important step towards an efficient regulation of Swiss occupational pension funds.

Finally, the regulator could conceive of establishing higher barriers to entry for pension schemes. These could, for example, be fit and proper conditions for the individuals managing the pension fund, as common for employees in other branches of the financial services industry such as banking. Participation in the Swiss pension fund market is currently not tied to specific criteria. Setting perquisites would likely lead to a consolidation, reducing the current number of funds from approximately 2,500 in $2008^{57}$ to a lower number which can be supervised more efficiently.

\section{Conclusion}

We adopt a stochastic pension fund model and combine it with a traffic light approach for solvency measurement purposes. The calibration and implementation of the model for a small sample of ten pension funds illustrates its application for the computation of probabilities and derivation of traffic light signals. The model adequately captures the particularities associated with the occupational pension fund system in Switzerland. Owing to its efficiency and ease of calibration it is well suited as a regulatory standard model in this very fragmented market, keeping costs of the

\footnotetext{
${ }^{57}$ See Swiss Federal Statistical Office under www.bfs.admin.ch.
} 
280

solvency test at a minimum, even for small pension funds with less sophisticated risk management know-how and infrastructure. In addition, a sensitivity analysis identifies important drivers of the shortfall probabilities and can thus assist the regulator with regard to specific decisions associated with the configuration of the framework.

However, some questions remain with respect to model design and calibration. First, we did not explicitly account for credit risk in the fund's asset portfolio. Therefore, the supervisory authority should exercise additional care with regard to solvency test results for pension funds with a relatively high proportion of defaultable instruments, such as corporate bonds, in their portfolio. Second, an incorporation of stochastic liabilities and different statistical distributions for the modeled asset classes could be discussed, although a departure from the associated assumptions would necessitate a switch from the closed-form to a numerical solution. Third, portfolio diversification and foreign currency exposure have to be borne in mind as critical factors with regard to the proposed calibration procedure. Finally, a practical implementation would need to be preceded by a comprehensive quantitative impact study for the majority of Swiss pension funds. Overall, we consider this straightforward framework to be an adequate first step towards a state-of-the-art solvency regulation of occupational pension funds in Switzerland.

\section{Acknowledgements}

We would like to thank two anonymous referees, Werner Nussbaum, and the participants of the World Risk and Insurance Economics Congress 2010 in Singapore, for their valuable comments and suggestions on this article. The authors gratefully acknowledge the financial support of the Swiss National Science Foundation SNF provided within the research grant "Regulation in the Financial Services Industry after the Crisis."

\section{References}

Bédard, D. and Dufresne, D. (2001) 'Pension funding with moving average rates of return', Scandinavian Actuarial Journal 1: 1-17.

Brombacher Steiner, M.V. (1999) 'The Swiss pension scheme: Long-term security through reform', Geneva Papers on Risk and Insurance-Issues and Practice 24(4): 488-494.

Bühlmann, H. (1996) Mathematical Methods in Risk Theory, 2nd edn. Berlin, Springer.

BVG (2009) 'Bundesgesetz über die berufliche Alters-, Hinterlassenen- und Invalidenvorsorge', (1 June), from http://www.admin.ch.

BVV2 (2009) 'Verordnung über die berufliche Alters-, Hinterlassenen- und Invalidenvorsorge', (1 June), from http://www.admin.ch.

Cairns, A.J.G. (1995) Pension funding in a stochastic environment: The role of objectives in selecting an asset allocation strategy, Heriot-Watt University working paper.

Cairns, A.J.G. (1996) Continuous-time pension-fund modelling, Heriot-Watt University working paper.

Cairns, A.J.G. (2000) 'Some notes on the dynamics and optimal control of stochastic pension fund models in continuous time', Astin Bulletin 30(1): 19-55.

Cairns, A.J.G. and Parker, G. (1997) 'Stochastic pension fund modelling', Insurance: Mathematics and Economics 21(1): 43-79.

Dufresne, D. (1988) 'Moments of pension contributions and fund levels when rates of return are random', Journal of the Institute of Actuaries 115: 535-544.

Dufresne, D. (1989) 'Stability of pension systems when rates of return are random', Insurance: Mathematics and Economics 8(1): 71-76. 
Dufresne, D. (1990) 'The distribution of a perpetuity, with applications to risk theory and pension funding', Scandinavian Actuarial Journal 9: 39-79.

Eling, M., Gatzert, N. and Schmeiser, H. (2008) 'The Swiss solvency test and its market implications', The Geneva Papers on Risk and Insurance - Issues and Practice 33(3): 418-439.

Gugler, P. (2005) 'The integrated supervision of financial markets: The case of Switzerland', The Geneva Papers on Risk and Insurance-Issues and Practice 30(1): 128-143.

Haberman, S. (1992) 'Pension funding with time delays: A stochastic approach', Insurance: Mathematics and Economics 11(3): 179-189.

Haberman, S. (1993a) 'Pension funding: The effect of changing the frequency of valuations', Insurance: Mathematics and Economics 13(3): 263-270.

Haberman, S. (1993b) 'Pension funding with time delays and autoregressive rates of investment return', Insurance: Mathematics and Economics 13(1): 45-56.

Haberman, S. (1994) 'Autoregressive rates of return and the variability of pension contributions and fund levels for a defined benefit pension scheme', Insurance: Mathematics and Economics 14(3): 219-240.

Haberman, S. (1997) 'Stochastic investment returns and contribution rate risk in a defined benefit pension scheme', Insurance: Mathematics and Economics 19(2): 127-139.

Haberman, S. and Sung, J.-H. (1994) 'Dynamic approaches to pension funding', Insurance: Mathematics and Economics 15(2-3): 151-162.

Mao, H., Ostaszewski, K.M. and Wang, Y. (2008) 'Risk analysis of mortality improvement: The case of Chinese annuity markets', The Geneva Papers on Risk and Insurance-Issues and Practice 33(2): 234-249.

O'Brien, T. (1986) 'A stochastic-dynamic approach to pension funding', Insurance: Mathematics and Economics 5(2): 141-146.

O'Brien, T. (1987) 'A two-parameter family of pension contribution functions and stochastic optimization', Insurance: Mathematics and Economics 6(2): 129-134.

OECD (2009) 'Pensions at a Glance: Retirement Income Systems in OECD Countries', from http:// www.oecd.org.

Officer, R.R. (1972) 'The distribution of stock returns', Journal of the American Statistical Association 67: 807-812.

Standard \& Poor's (2009) '2008 Annual Global Corporate Default Study and Rating Transitions', from http://www.standardandpoors.com.

Swiss Federal Statistical Office (2009) 'Pensionskassenstatistik: Struktur der beruflichen Vorsorge in der Schweiz', from http://www.bfs.admin.ch.

Swisscanto (2008) 'Schweizer Pensionskassen', from http://www.swisscanto.ch/ch/en.

Yang, S.S. and Huang, H.-C. (2009) 'The impact of longevity risk on the optimal contribution rate and asset allocation for defined contribution pension plans', The Geneva Papers on Risk and Insurance-Issues and Practice 34(4): 660-681.

Zimbidis, A. and Haberman, S. (1993) 'Delay, feedback and variability of pension contributions and fund levels', Insurance: Mathematics and Economics 13(3): 271-285.

\section{About the Authors}

Alexander Braun obtained the degree Diplom-Kaufmann from the University of Mannheim in 2007. Between 2007 and 2009, he worked as Senior Analyst in fixed income for the European Capital Markets Division of Lehman Brothers in London. In February 2009 he joined the Institute of Insurance Economics at the University of St. Gallen, Switzerland, where he is currently enrolled in the $\mathrm{PhD}$ programme in Finance. His research interests are centred around insurance products related to the capital markets, risk management, as well as regulation of banks and insurance companies.

Przemysław Rymaszewski studied Business Administration at the University of Cologne and the Stockholm School of Economics. Since 2009 he has been Project 
Manager and PhD candidate at the Institute of Insurance Economics, University of St. Gallen. His main research interests cover topics in Regulation and Supervision, Risk Management, Guaranty Funds, and Solvency Issues.

Hato Schmeiser studied business administration at the University of Mannheim. After his doctoral degree and postdoctoral lecture qualification (Habilitation) in 2003 (Humboldt Universität zu Berlin), he was appointed Professor for Insurance and Risk Management at the University of Münster. Since 2005 he has been Chair for Risk Management and Insurance and Managing Director of the Institute of Insurance Economics at the University of St. Gallen. His main research interests include individual financial planning, dynamic financial analysis, option pricing and regulation of financial firms. Current Research Fields can be found via: www.ivw.hsg.ch 